\title{
Airway management after failure to intubate by direct laryngoscopy: outcomes in a large teaching hospital
}

\author{
[Le contrôle des voies aériennes après l'échec de l'intubation par laryngoscopie \\ directe : résultats obtenus dans un grand hôpital universitaive]
}

Christopher M. Burkle MD, Michael T. Walsh MD, Barry A. Harrison MD, Timothy B. Curry MD PhD, Steven H. Rose MD

Purpose: The purpose of this single-centre database review was to establish the incidence of failure to intubate by direct laryngoscopy, to measure morbidity and mortality associated with this event, and to examine the use and efficacy of alternative airway devices.

Methods: Difficult intubation via direct laryngoscopy at Mayo Clinic Rochester is recorded in an electronic database using a functional classification: 0 = no difficulty; 1 = mild to moderate difficulty; and 2 $=$ severe difficulty often requiring a change in intubation technique. Using this database, the total number of intubations was determined for a selected review period and the incidence of failure to intubate by direct laryngoscopy was established. Abstraction of chart data allowed for determination of associated morbidity and mortality, success of alternative airway devices, and case cancellation rate.

Results: During the period from August I, 200 I through December 31, 2002, 37,482 patients underwent general anesthesia with attempted direct laryngoscopy. One hundred sixty-one patients $(0.43 \%)$ could not be intubated by direct laryngoscopy alone. Morbidity associated with difficult intubation included soft tissue/dental damage $(n=8)$, intraoperative cardiac arrest $(n=1)$, and possible aspiration $(n=1)$. Three patients required intensive care unit admission. There was no associated mortality. The most commonly used alternative airway device was the flexible fibreoptic scope. Five case cancellations resulted from failure to intubate with alternative devices.

Conclusion: The rate of unexpected failure to intubate by direct laryngoscopy is essentially unchanged from earlier studies. While morbidity was low, continued education and early use of alternative difficult airway devices may further limit complications associated with this event.
Objectif : Établir, par une revue de la base de données d'un seul centre, la fréquence des échecs à intuber par laryngoscopie directe, mesurer la morbidité et la mortalité associées et vérifier l'usage et l'efficacité d'autres instruments d'intubation.

Méthode : Les cas d'intubation difficile par laryngoscopie directe à la clinique Mayo de Rochester ont été notés dans une base de données électronique selon une classification fonctionnelle : 0 = aucune difficulté ; 1 = difficulté légère à modérée et 2 = difficulté sévère exigeant souvent le recours à d'autres techniques d'intubation. Le nombre total d'intubations a été déterminé pour une période de révision choisie et la fréquence des échecs à intuber par laryngoscopie directe a été établie. Un résumé analytique des données a permis de déterminer la morbidité et la mortalité associées, le succès des autres techniques et le taux d'annulation.

Résultats : Du premier août 200I au 3 I décembre 2002, 37482 patients ont eu une anesthésie générale et subi une laryngoscopie directe. Cent soixante et un patients (0,43\%) n'ont pu être intubés par laryngoscopie directe seulement. La morbidité associée à l'intubation difficile comprenait une lésion des tissus mous/des dents $(n=8)$, un arrêt cardiaque peropératoire $(n=1)$ et une aspiration possible $(n=1)$. Trois patients ont dû être admis à l'unité des soins intensifs. Il n'y a pas eu de mortalité associée. L'instrument de remplacement le plus souvent utilisé a été le fibroscope flexible. Cinq annulations ont résulté de l'échec à intuber avec d'autres instruments.

Conclusion : Le taux imprévu d'échec à intuber par laryngoscopie directe est essentiellement le même depuis les études antérieures. La morbidité est faible, mais une formation continue et un usage précoce d'autres instruments réduiraient davantage les complications qui y sont associées.

From the Department of Anesthesiology, Mayo Clinic College of Medicine, Rochester, Minnesota, USA.

Address correspondence to: Dr. Christopher M. Burkle, Department of Anesthesiology, Mayo Clinic, 200 First Street S.W., Rochester, Minnesota 55905, USA. Phone: 507-284-9695; Fax: 507-284-0120; E-mail: burkle.christopher@mayo.edu

Department and institution to which the work should be attributed: Department of Anesthesiology, Mayo Clinic, Rochester, Minnesota, USA.

Financial support: Support was provided solely from institutional and/or departmental sources. Accepted for publication August 19, 2004.

Revision accepted February 8, 2004. 
A

IRWAY management is of paramount importance in the practice of anesthesia. The large number of studies which have attempted to quantify the incidence of difficult intubation and/or describe associated risk factors demonstrates this fact. ${ }^{1-12}$ Despite the importance of this subject, there is no uniform definition of the difficult airway. ${ }^{13}$ Previous definitions include number of laryngoscopy attempts, duration of laryngoscopy attempts, and laryngoscopic view. Several scoring systems have been introduced incorporating multiple objective and subjective factors. Considering the variety of definitions, it is not surprising the incidence of difficult intubation ranges from 1.5 to $13 \% .{ }^{1}$ However, the incidence of failure to intubate ranges more narrowly. ${ }^{2-5}$

Respiratory events during anesthesia comprise the largest class of injury in the American Society of Anesthesiologists (ASA) Closed Claims Project. ${ }^{6}$ Inadequate ventilation, esophageal intubation, and difficult tracheal intubation were reported to be the most common causes of adverse respiratory outcomes. Airway trauma associated with difficult intubation was cited in nearly $50 \%$ of these cases. These data are recorded only from medico-legal cases, introducing selection bias and making any calculation of the overall incidence with which this occurs unreliable. In one review of 18,500 intubations, Rose and Cohen concluded that difficult tracheal intubations ( $>$ two laryngoscopy attempts) were associated with increased trauma to the airway. ${ }^{3}$

We undertook a large single-centre study to determine the incidence of unexpected failure to intubate by direct laryngoscopy, the morbidity and mortality associated with this event, and the efficacy of alternative airway devices in this setting.

\section{Materials and methods}

After Mayo Clinic Rochester Institutional Review Board approval, patients undergoing general endotracheal anesthesia between August 2001 and December 2002 were identified retrospectively by use of the Mayo Clinic Rochester Department of Anesthesia computerized intraoperative anesthesia record database. The Mayo Clinic Department of Anesthesia has employed a numerical intubation scoring system called the Mayo intubation scoring system (MISS) to describe the difficulty of intubation by direct laryngoscopy since 1984 (Table I). The total number of patients who underwent attempted direct laryngoscopy over the study period was established from the combined total of all MISS scores.

Hospital records of all patients with MISS scores of " 2 " were individually reviewed by one of three study coordinators (C.B., M.W., T.C.). Only those patients who had given consent for use of their hospital charts for research purposes were included.

Information from each chart was recorded on an Excel spreadsheet. Data were divided into three general sections: 1) incidence of unexpected failure to intubate by direct laryngoscopy; 2) intraoperative management of the unexpected difficult intubation; 3 ) morbidity and 30-day mortality associated with unexpected difficult intubation and its management. Intraoperative management data abstracted included the ability to ventilate, incidence of case cancellation, a change to regional anesthesia, a change to monitored anesthesia care, types of intubating devices used in subsequent attempts, and final equipment choice used to successfully intubate the trachea. Morbidity associated data included unexpected intensive care unit (ICU) admission, acute myocardial infarction, cardiac arrest, cerebral vascular event, aspiration, pneumothorax, airway/dental trauma, and intraoperative death. If present, each of these adverse events was further reviewed to determine if they were a direct result of difficult intubation. Likewise, deaths within 30-days of a difficult intubation were reviewed to see if the death was due to airway-related causes. If data was incomplete for a patient it was noted and the patient's information was not included in the final tabulation of incidence or outcome results.

\section{Statistical analysis}

Statistical analysis was performed using a Pearson goodness of fit Chi-square test with the threshold of significance set at $P<0.05$.

\section{Results}

Of 37,483 patients undergoing planned general anesthesia between August 1, 2001 and December 31, 2002, 187 patients received a MISS score of " 2 " indicating endotracheal intubation was severely difficult (Table II). The chart of one of these patients had incomplete data and was excluded from the study. All patients who were found to be difficult to intubate had provided prior approval for the use of their chart for this purpose. Our obstetrical population comprises less than $1 \%$ of patients undergoing general anesthesia and was not included in our study. Twenty-six patients were given a MISS score of " 2 " but after reviewing their charts were found not to represent failure to intubate by direct laryngoscopy and were excluded from analysis. In 25 of these patients a direct laryngoscopy was never attempted, as an alternative means of intubation was chosen primarily. These patients should not have received any score since the system 
TABLE I Mayo intubation scoring system (MISS)

\begin{tabular}{|c|c|c|c|}
\hline Score & Definition & Description & Future airway implications \\
\hline$\overline{0}$ & $\begin{array}{l}\text { No difficulty } \\
\text { with intubation }\end{array}$ & $\begin{array}{l}\text { Straight forward laryngoscopy } \\
\text { and endotracheal intubation }\end{array}$ & $\begin{array}{l}\text { No anticipated problems for } \\
\text { intubation }\end{array}$ \\
\hline 1 & $\begin{array}{l}\text { Moderate } \\
\text { difficulty } \\
\text { with } \\
\text { intubation }\end{array}$ & $\begin{array}{l}\text { Changes of patient position } \\
\text { and/or practitioners and/or } \\
\text { multiple attempts before } \\
\text { successful intubation }\end{array}$ & $\begin{array}{l}\text { Anticipate potential problems } \\
\text { with intubation, consider } \\
\text { alternative technique }\end{array}$ \\
\hline 2 & $\begin{array}{l}\text { Severe } \\
\text { difficulty } \\
\text { with } \\
\text { intubation }\end{array}$ & $\begin{array}{l}\text { An altenative technique is } \\
\text { often used to intubate, } \\
\text { i.e., bougie, fibreoptic } \\
\text { technique, or LMA } \\
\text { technique }\end{array}$ & $\begin{array}{l}\text { Anticipate problems with intubations, } \\
\text { use alternative technique. Requires } \\
\text { documentation of difficult airway } \\
\text { in the patient's discharge summary as } \\
\text { well as offering the patient a } \\
\text { MedicAlert } \AA \text { bracelet }\end{array}$ \\
\hline
\end{tabular}

LMA = laryngeal mask airway

TABLE II Incidence and outcome of difficult intubation

\begin{tabular}{lll}
\hline Severe difficulty with intubation & $186 / 37,482$ & $0.5 \%$ \\
Failed intubation & $161 / 37,482$ & $0.4 \%$ \\
Airway successfully established by & $155 / 37,482$ & $0.4 \%$ \\
secondary means & & \\
Case cancelled & $5 / 161$ & $3.1 \%$ \\
Change to regional & $1 / 161$ & $0.6 \%$ \\
\hline
\end{tabular}

$37,482=$ total number of patients.

was designed to grade difficulty of direct laryngoscopy. In one case a "2" score was associated with successful intubation by direct laryngoscopy alone; after repeated attempts at direct laryngoscopy with downward cricoid pressure and blind placement of the endotracheal tube. Therefore, intubation by direct laryngoscopy failed in 161 patients or $0.43 \%$ of the cases. The average number of direct laryngoscopy attempts per patient was 2.2 however, there was a $17 \%$ rate of incomplete documentation. Of those patients who could not be intubated by direct laryngoscopy, five patients $(3.1 \%)$ had their surgery cancelled or postponed. A decision to employ a regional anesthetic technique was made in one case $(0.6 \%$; Table II).

Flexible fibreoptic intubation was the preferred alternative approach in managing patients who could not be intubated by direct laryngoscopy (Table III). In 99 of 161 patients $(61.5 \%)$, the flexible fibreoptic bronchoscope was used at some point in the management course. This alternative succeeded in 92 of 99 (92.9\%) cases. No attempt was made to distinguish if flexible fibreoptic intubation was performed while the patient was spontaneously breathing, awakened, or still under general anesthesia. One patient was successfully man-
TABLE III Final techniques in successful airway establishment $(n=155$ cases $)$

\begin{tabular}{lll}
\hline Technique & $n$ & $(\%)$ \\
\hline Flexible fibreoptic & 92 & $(59.4)$ \\
Bougie & 32 & $(20.6)$ \\
LMA & 10 & $(6.5)$ \\
Intubating LMA & 18 & $(11.6)$ \\
Wu Scope & 1 & $(0.6)$ \\
Tracheostomy & 1 & $(0.6)$ \\
Other & $1^{*}$ & $(0.6)$ \\
\hline
\end{tabular}

*Cuffed oropharyngeal airway. LMA = laryngeal mask airway.

aged with a conventional laryngeal mask airway (LMA), and three with intubating LMAs. One patient underwent tracheostomy. Two cases of failed fibreoptic intubation resulted in cancellation of surgery.

Three patients required unplanned ICU admission for monitoring of complications related to difficult airway management (Table IV). Seven additional patients suffered upper-airway soft tissue injury and/or dental damage that did not require ICU monitoring (Table V). None of the patients in our study suffered long-term sequelae or mortality related to difficult airway management.

\section{Discussion}

Successful management of the unanticipated difficult airway is critically important in the practice of anesthesia. Many studies suggest techniques to improve accuracy in the preoperative prediction of intubation difficulty. ${ }^{2,7-12}$ However, the success of these strategies is limited and unexpected difficult airways continue to be a leading cause of morbidity, mortality, and litiga- 
TABLE IV Summary of ICU admissions

$\begin{array}{ll}\text { Patient\#1 } & \begin{array}{l}\text { Cardiac arrest during urgent re-establishment of a previous tracheostomy due to dyspnea during which direct laryngoscopy } \\ \text { was unsuccessful and attempts at emergent tracheostomy were complicated by malpositioning of the tracheostomy tube. The } \\ \text { patient developed hypoxemia, profound bradycardia, and the need for chest compressions before the tracheostomy could be } \\ \text { successfully completed. The patient was returned to the ICU and ultimately discharged without further complication. }\end{array} \\ \text { Patient\#2 } & \begin{array}{l}\text { Vocal cord swelling following several intubation attempts by direct laryngoscopy. The patient remained intubated in the ICU } \\ \text { until postoperative day three to allow airway edema to subside and was subsequently extubated without incident. }\end{array} \\ \text { Patient\#3 } \begin{array}{l}\text { Concerns related to possible aspiration following multiple attempts at intubation. This patient did not develop respiratory } \\ \text { compromise and remained in the ICU for one day after surgery. }\end{array}\end{array}$

$\mathrm{ICU}=$ intensive care unit.

TABLE V Adverse outcomes

\begin{tabular}{|c|c|c|}
\hline & Events & $\begin{array}{l}\text { Direct airway } \\
\text { management cause }\end{array}$ \\
\hline Dental or airway soft tissue injury & $8(5.0)$ & 8 \\
\hline Unplanned ICU admission** & $3(1.9)$ & 3 \\
\hline Acute myocardial infarction & 0 & \\
\hline Cardiac arrest & $1(0.6)$ & 1 \\
\hline Cerebrovascular accident & 0 & \\
\hline Aspiration & 0 & \\
\hline Pneumothorax & 0 & \\
\hline Death within 30 days & 0 & \\
\hline
\end{tabular}

*Total number of severely difficult intubations $=161 ;$ * Two patients also included in airway soft tissue injury and cardiac arrest column. ICU $=$ intensive care unit.

tion in anesthetic practice. ${ }^{6,14,15}$ Previous studies report a narrow range of failure to intubate by direct laryngoscopy of between 0.04 and $0.3 \% \%^{2,3}$ In the largest study to date, we state a rate of $0.43 \%$. Our outcome data might suggest that predicting which patients will be difficult to intubate by direct laryngoscopy may never approach exactness.

In 1991, the ASA Closed Claims Project published an analysis of "adverse respiratory events in anesthesia." 15 Thirty-four percent of all claims were related to respiratory events and an even larger proportion of serious events (brain injury and death) were due to respiratory complications. The most common respiratory events $(75 \%)$ were inadequate ventilation, esophageal intubation, and difficult intubation. In a follow-up report in 1999, a decrease in esophageal intubation and inadequate ventilation claims was reported. ${ }^{16}$ This was attributed to better monitoring. Despite heightened awareness, the percentage of claims for difficult intubation was essentially unchanged. Predicting difficult intubations may thus be an elusive goal. ${ }^{14}$ Most studies evaluating preoperative evaluation of the airway, including those of Rose and Cohen, show a poor positive predictive value for the commonly used tests to predict difficult intubation.
The ASA task force on management of the difficult airway has defined difficult laryngoscopy as being unable "to visualize any portion of the vocal cords with conventional laryngoscopy" and defined difficult intubation as "an airway that requires more than three attempts or more than ten minutes to secure by direct laryngoscopy." 13,17 Most studies focus on either the view of the larynx as defined by Cormack and Lehane, or the number of intubation attempts. ${ }^{3,18-23}$

A common criticism of these studies is defining or standardizing the laryngoscopy attempt based upon technique (e.g., position of the patient, use of muscle relaxants, use of external laryngeal manipulation) ${ }^{24}$ It is often unclear if the view recorded was the first view or the best view obtained after optimization of the technique. Other criticisms have focused on the Cormack-Lehane grading system and its modifications. ${ }^{14,16}$ It is difficult to control these factors, even prospectively.

Our study is unique in that it reports only failure to intubate using direct laryngoscopy, a clinically important, well-defined end-point. We studied our current clinical practice and made no attempt to document best laryngeal view, patient position, or degree of paralysis as these are difficult or impossible to control. We assumed each anesthesiologist used his or her best clinical judgement in deciding to induce general anesthesia and attempt direct laryngoscopy. We also assumed every effort was made to achieve the best possible view, conditions for intubation by direct laryngoscopy were optimized, and the staff anesthesiologist used his or her best judgement in deciding when to change to an alternate technique. This study was performed at a large teaching hospital where initial attempts at direct laryngoscopy may have been made by residents, student nurse anesthetists, or certified nurse anesthetists prior to attempts by the staff anesthesiologist. Like any large anesthesia department, skill and experience varies in both direct laryngoscopy and the use of alternative airway devices. The Mayo Clinic Department of Anesthesia Advanced Airway Management Laboratory and several intra- 
TABLE VI Failure to intubate by direct laryngoscopy

\begin{tabular}{|c|c|c|c|c|c|}
\hline Author & Year published & Duration & Patients (n) & Failed intubation & Outcome \\
\hline Samsoon/Young ${ }^{2}$ & 1987 & three years & 13,300 & $0.04 \%$ & \\
\hline Rose/Cohen ${ }^{3}$ & 1994 & 27 months & 18,205 & $0.3 \%$ & $\begin{array}{l}0.05 \% \\
\text { surgery cancelled }\end{array}$ \\
\hline Rose/Cohen ${ }^{4}$ & 1996 & 7 months & 3,325 & $0.1 \%$ & \\
\hline Burkle* & 2005 & 16 months & 37,483 & $0.43 \%$ & $\begin{array}{l}0.01 \% \\
\text { surgery cancelled }\end{array}$ \\
\hline
\end{tabular}

*Authors' present article.

TABLE VII Difficult airway cart equipment

LMA Classic ${ }^{\mathrm{TM}}$

Intubating (Fastrach $\left.{ }^{\mathrm{TM}}\right) \mathrm{LMA}^{\mathrm{TM}}$

Bougie (intubating stylet)

Bullard laryngoscope ${ }^{\circledR}$

Wu Scope ${ }^{\circledR}$

Flexible fibreoptic scope

Trachlite $^{\mathrm{TM}}$

Combitube $^{\mathrm{TM}}$

Retrograde intubation kit

Percutaneous cricothyrotomy kit

Transtracheal jet ventilation kit

LMA = laryngeal mask airway

departmental difficult airway courses are readily available to all anesthesia providers to practice the skills necessary to manage the unanticipated difficult intubation. Although some feel that the successful use of a bougie to secure the airway does not qualify as failure to intubate, we chose to establish an overall incidence without the use of alternative airway instruments. We studied only patients who were deemed acceptable risks to proceed with induction and direct laryngoscopy as the primary plan for airway management e.g., the unanticipated difficult airway by direct laryngoscopy.

The overall incidence of inability to intubate by direct laryngoscopy is slightly higher than reported in previous studies (Table VI). Rose and Cohen studied 3,325 patients and reported a failed intubation rate of $0.1 \%{ }^{4}$ Of note, $0.5 \%$ of their patients had four or more attempts at laryngoscopy. In a larger study, the failure rate was $0.3 \%$ while $0.4 \%$ required four or more laryngoscopy attempts. ${ }^{3}$ The higher incidence we report may be due to recent emphasis on fewer attempts at laryngoscopy and more rapid transition to alternate techniques. The average number of attempts of direct laryngoscopy per patient in our study was 2.2 , however poor documentaion was apparent in $17 \%$ of all reported cases. Several authors have suggested repeated laryngoscopy can cause trauma and edema to the airway, making a bad situation (can't intubate) worse (can't intubate, can't ventilate). ${ }^{3,25,26}$ Mort examined the records of 2,833 patients emergently intubated outside the operating room and found increased airway related complications (hypoxia, regurgitation, aspiration) when three or more direct laryngoscopies were needed for successful intubation. ${ }^{27}$ While causality could not be established, the study suggests an early alternative approach to intubation may be prudent. Ready access to sophisticated airway equipment and assistance available at our institution may also have influenced the original decision on whether to induce general anesthesia and attempt direct laryngoscopy or proceed directly to an alternative means of intubation. The widespread use and effectiveness of the LMA as an alternative device might allow a more aggressive approach in borderline patients reducing overall failures to establish an airway but raising the failure rate of direct laryngoscopy.

Our results indicate alternative intubation techniques may be used successfully to secure the airway after failure to intubate by direct laryngoscopy. During the period reviewed in this study, all sites in our facility where anesthesia care was delivered were provided immediate access (difficult airway equipment cart within 100 feet) to many different types of emergency airway devices (Table VII). Flexible fibreoptic intubation was the preferred alternative approach in managing patients who could not be intubated by direct laryngoscopy. Similar patterns have been described elsewhere but this approach may vary according to practice. ${ }^{28}$ The success rate of this preferred alternative approach at our institution was high (91\%). The efficacy of immediately available alternative airway devices is further demonstrated by our low cancellation rate. Only five cases $(3.1 \%)$ were postponed or cancelled because of failed direct laryngoscopy. Over the past decade, considerable emphasis has been placed on techniques to manage the difficult airway as demonstrated by the plethora of airway 
workshops and types of equipment to facilitate ventilation and intubation. The low rate of case cancellations in our study suggests improved recognition of the role of alternative airway devices and expertise in their use over time. We saw no use of transtracheal jet ventilation, long a mainstay of the ASA difficult airway algorithm, although there was no case in which the patient could not be intubated or ventilated, the primary indication for transtracheal jet ventilation.

We report little morbidity related to unexpected difficult intubation (Table III). Dental injury and airway soft tissue injury made up the largest percentage of morbidity in our study. From work done earlier by Warner et al., we know dental injury is more common in patients who are difficult to intubate. ${ }^{29}$ Airway injury may occur even after uneventful intubation. However, the events we report appear to be a direct result of difficult airway management. ${ }^{30}$ Rose and Cohen reported higher rates of oxygen desaturation and hypertension, as well as an increased incidence of dental injury and ICU admission, in patients who were difficult to intubate. ${ }^{3}$ Our retrospective study did not establish an incidence of oxygen desaturation or hypertensive episodes during airway management. Major morbidity resulting in ICU admission, such as myocardial infarction, significant dysrhythmias, or neurologic injury would likely be documented. The higher rate of failed intubation observed in our study may be a result of earlier institution of alternative methods to secure the airway. Early use of these devices may have resulted in a lower complication rate than would have occurred with further attempts at direct laryngoscopy. We also found no longterm sequelae or mortality as a result of difficult intubation. These are rare events and a larger study may be required to establish the incidence of such occurrences.

Our study has several limitations. First, it is retrospective in nature. As a result we selected simple, welldefined end-points such as inability to intubate. Most of the factors not controlled in this retrospective study are difficult to control, even with a prospective study design. For example, it is nearly impossible to control for preoperative assessment of intubation, as most tests have a large inter-observer variability. It is also difficult to ensure complete data entry in studies that include a large number of anesthesia personnel, conducted over a number of years. Optimal positioning and conditions for intubation, practitioner skill and experience, and individual clinical judgement are also difficult to control. Protocols are susceptible to clinical judgement in assessing the airway before and during intubation attempts. The biggest variable may be deciding when to pursue alternate techniques. We wanted to study the reality of clinical practice at our institution. As a large academic institution, our practice may not fairly represent the mainstream practices seen at other facilities. We felt that by having alternative airway devices readily available, this setting may enable a more conservative approach towards the patient deemed difficult to intubate by direct laryngoscopy.

This study suggests that we may have maximized our clinical ability to predict difficult intubation by direct laryngoscopy. The rate of this event is low but unlikely ever to approach zero. Increased familiarity with, and accessibility to alternate techniques may result in their increased and earlier use during the intubation attempts. In our study, minor upper airway trauma and dental injury secondary to direct laryngoscopy attempts were the most commonly observed complications. Should multiple attempts at direct laryngoscopy be avoided? This question remains unanswered. Perhaps emphasis should be directed towards encouraging a ready willingness to apply alternative, practiced techniques early after failed intubation by direct laryngoscopy, thereby minimizing trauma to the airway and decreasing the risks of airway compromise and resulting morbidity.

\section{References}

1 Randell $T$. Thyromental distance - shouldn't we redefine its role in the prediction of difficult laryngoscopy (Letter, reply). Acta Anaesthesiol Scand 1998; 42: 136-7.

2 Samsoon GL, Young JR. Difficult tracheal intubation: a retrospective study. Anaesthesia 1987; 42: 487-90.

3 Rose DK, Cohen MM. The airway: problems and predictions in 18,500 patients. Can J Anaesth 1994; 41: 372-83.

4 Rose DK, Coben MM. The incidence of airway problems depends on the definition used. Can J Anaesth 1996; 43: 30-4.

5 Combes X, Le Roux B, Suen P, et al. Unanticipated difficult airway in anesthetized patients: prospective validation of a management algorithm. Anesthesiology 2004; 100: 1146-50.

6 Caplan RA, Posner KL, Ward RJ, Cheney FW. Adverse respiratory events in anesthesia: a closed claims analysis. Anesthesiology 1990; 72: 828-33.

7 Oates JD, Macleod AD, Oates PD, Pearsall FJ, Howie JC, Murray GD. Comparison of two methods for predicting difficult intubation. Br J Anaesth 1991; 66: 305-9.

8 Mallampati SR, Gatt SP, Gugino LD, et al. A clinical sign to predict difficult tracheal intubation: a prospective study. Can Anaesth Soc J 1985; 32: 429-34.

9 Wilson ME, Spiegelhalter D, Robertson JA, Lesser $P$. Predicting difficult intubation. Br J Anaesth 1988; 61: 211-6. 
10 Karkouti K, Rose DK, Ferris LE, Wigglesworth DF, Meisami-Fard T, Lee $H$. Inter-observer reliability of ten tests used for predicting difficult tracheal intubation. Can J Anaesth 1996; 43: 554-9.

11 Fisher A, Waterhouse TD, Adams AP. Obesity: its relation to anaesthesia. Anaesthesia 1975; 30: 633-47.

12 Benumof JL. Obstructive sleep apnea in the adult obese patient: implications for airway management. J Clin Anesth 2001; 13: 144-56.

13 Anonymous. Practice guidelines for management of the difficult airway. An updated report by the American Society of Anesthesiologists Task Force on Management of the Difficult Airway. Anesthesiology 2003; 98: 1269-77.

14 Yentis SM. Predicting difficult intubation - worthwhile exercise or pointless ritual? (Editorial). Anaesthesia 2002; 57: 105-9.

15 Cheney FW, Posner KL, Caplan RA. Adverse respiratory events infrequently leading to malpractice suits. A closed claims analysis. Anesthesiology 1991; 75: 932-9.

16 Cheney FW. The American Society of Anesthesiologists Closed Claims Project. What have we learned, how has it affected practice, and how will it affect practice in the future? Anesthesiology 1999; 91: 552-6.

17 Anonymous. Practice guidelines for management of the difficult airway. A report by the American Society of Anesthesiologists Task Force on Management of the Difficult Airway. Anesthesiology 1993; 78: 597-602.

18 Asai T, Koga K, Vaughan RS. Respiratory complications associated with tracheal intubation and extubation. Br J Anaesth 1998; 80: 767-75.

19 Koh LK, Kong CF, Ip-Yam PC. The modified Cormack-Lehane score for the grading of direct laryngoscopy: evaluation in the Asian population. Anaesth Intensive Care 2002; 30: 48-51.

20 Savva D. Prediction of difficult tracheal intubation. $\mathrm{Br}$ J Anaesth 1994; 73: 149-53.

21 Tse JC, Rimm EB, Hussain A. Predicting difficult endotracheal intubation in surgical patients scheduled for general anesthesia: a prospective blind study. Anesth Analg 1995; 81: 254-8.

22 Yentis SM, Lee DJ. Evaluation of an improved scoring system for the grading of direct laryngoscopy. Anaesthesia 1998; 53: 1041-4.

23 Cormack RS, Lehane J. Difficult tracheal intubation in obstetrics. Anaesthesia 1984; 39: 1105-11.

24 Williamson $R$. Predicting difficult laryngoscopy (Letter). Can J Anaesth 1996; 43: 1082.

25 Fasting S, Gisvold SE. Serious intraoperative problems a five-year review of 83,844 anesthetics. Can J Anesth 2002; 49: 545-53.

26 Crosby ET, Cooper RM, Douglas MJ, et al. The unanticipated difficult airway with recommendations for man- agement. Can J Anaesth 1998; 45: 757-76.

27 Mort TC. Emergency tracheal intubation: complications associated with repeated laryngoscopic attempts. Anesth Analg 2004; 99: 607-13.

28 Jenkins K, Wong DT, Correa R. Management choices for the difficult airway by anesthesiologists in Canada. Can J Anesth 2002; 49: 850-6.

29 Warner ME, Benenfeld SM, Warner MA, Schroeder DR, Maxson PM. Perianesthetic dental injuries. Frequency, outcomes, and risk factors. Anesthesiology 1999; 90: 1302-5.

30 Weber $S$. Traumatic complications of airway management. Anesthesiol Clin North America 2002; 20:

503-12. 